\title{
Ontogeny and water temperature influences the antiviral response of the Pacific oyster, Crassostrea gigas
}

\author{
Timothy J. Green ${ }^{\mathrm{a}, *}$, Caroline Montagnani ${ }^{\mathrm{b}}$, Kirsten Benkendorff ${ }^{\mathrm{c}}$, Nick Robinson ${ }^{\mathrm{a}, \mathrm{d}}$, Peter Speck ${ }^{\mathrm{a}}$
}

\author{
a School of Biological Sciences and Australian Seafood Cooperative Research Centre, Flinders University, GPO \\ Box 2100, Adelaide, SA 5001, Australia \\ b Ifremer, UMR 5119 Ecology of Coastal Marine Systems, Université Montpellier 2, Place Eugène Bataillon, \\ CC80, 30495 Montpellier cedex 05, France \\ ${ }^{c}$ Marine Ecology Research Centre, Southern Cross University, P.O. Box 157, Lismore, NSW 2480, Australia \\ d Nofima, P.O. Box 210, N-1431 Ås, Norway \\ *: Corresponding author : Timothy J. Green, email address : tim.green@flinders.edu.au
}

\begin{abstract}
:
Disease is caused by a complex interaction between the pathogen, environment, and the physiological status of the host. Determining how host ontogeny interacts with water temperature to influence the antiviral response of the Pacific oysters, Crassostrea gigas, is a major goal in understanding why juvenile Pacific oysters are dying during summer as a result of the global emergence of a new genotype of the Ostreid herpesvirus, termed OsHV-1 $\mu \mathrm{var}$. We measured the effect of temperature (12 vs $22^{\circ} \mathrm{C}$ ) on the antiviral response of adult and juvenile $C$. gigas injected with poly I:C. Poly I:C upregulated the expression of numerous immune genes, including TLR, MyD88, IKB-1, Rel, IRF, MDA5, STING, SOC, PKR, Viperin and Mpeg1. At $22^{\circ} \mathrm{C}$, these immune genes showed significant upregulation in juvenile and adult oysters, but the majority of these genes were up-regulated $12 \mathrm{~h}$ postinjection for juveniles compared to $26 \mathrm{~h}$ for adults. At $12{ }^{\circ} \mathrm{C}$, the response of these genes was completely inhibited in juveniles and delayed in adults. Temperature and age had no effect on hemolymph antiviral activity against herpes simplex virus (HSV-1). These results suggest that oysters rely on a cellular response to minimise viral replication, involving recognition of virus-associated molecular patterns to induce host cells into an antiviral state, as opposed to producing broad-spectrum antiviral compounds. This cellular response, measured by antiviral gene expression of circulating hemocytes, was influenced by temperature and oyster age. We speculate whether the vigorous antiviral response of juveniles at $22{ }^{\circ} \mathrm{C}$ results in an immune-mediated disorder causing mortality.
\end{abstract}

\section{Highlights}

We investigate the immune response of Crassostrea gigas against poly I:C. Poly I:C induces expression of TLR, MDA-5, Rel, IRF, STING, PKR, Viperin. - Hemolymph anti-HSV-1 activity is not induced by poly I:C. Temperature and host ontogeny influence the oyster's antiviral response. Juvenile oysters at $22{ }^{\circ} \mathrm{C}$ respond vigorously to poly I:C.

Keywords : Crassostrea ; OsHV-1 ; Water temperature ; Antiviral response ; Herpesvirus 


\subsection{Introduction}

Aquatic diseases involve complex interactions between pathogen, the prevailing environment, and host physiological status. Despite this, many scientific studies on aquatic diseases only investigate the effect of one or two simultaneous factors [1]. This creates problems in interpreting the causes of multifactorial diseases, such as Pacific oyster mortality syndrome (POMS), a worldwide and complex phenomenon affecting the Pacific oyster, Crassostrea gigas [2-4]. This disease has coincided with the global emergence of a new genotype of the Ostreid herpesvirus, termed OsHV-1 $\mu$ var $[2,3,5]$, and the disease has been attributed to the "massive mortalities" that have occurred in France and "juvenile oyster mortality (JOM)" in New Zealand. Epidemiological studies demonstrated that younger oysters (spat $>$ juveniles $>$ adults) are more susceptible to OsHV-1 $\mu$ var [6-8], and that the onset of disease occurs when seawater temperatures exceed $17^{\circ} \mathrm{C}[4,7,8]$. Aquaculture selection programs have shown differential survival of C. gigas family lines exposed to OsHV-1 $\mu$ var [9], establishing that there is a unidentified genetic component(s) affecting resistance to the disease.

It is unknown why younger developmental stages of $C$. gigas are more susceptible to OsHV-1 $\mu$ var. One possibility is they have an immature immune system $[2,10]$. Alternatively, replication of OsHV-1 $\mu$ var is reliant on host cell replication machinery and the higher cell replication rates of immature oysters could favour the virus. Seawater temperature above $16^{\circ} \mathrm{C}$ is a risk factor $[7,8,11,12]$, and it is presumed that OsHV-1 causes asymptomatic (latent) infections below this temperature [10]. This presumption is based on observations of herpesvirus infection in fish. For example, carp exposed to Koi herpesvirus (KHV) at $11^{\circ} \mathrm{C}$ do not succumb to the disease until water temperature is elevated to $23^{\circ} \mathrm{C}$, and these fish do not shed the virus and infect naïve fish during co-habitation experiments unless temperatures are above $20^{\circ} \mathrm{C}$, suggesting the virus is in an altered transcriptional state below $20^{\circ} \mathrm{C}$ [13]. Seawater temperature would not only influence the pathogen, but would also increase the metabolism of the host $[1,14]$. A trade-off for increasing the host's metabolic requirements is less energy and resources available for maintaining the host's immunological status [14]. It is therefore not surprising that C. gigas also suffer mortalities from other pathogens, such as Vibrio bacteria, when the seawater temperature rises above $18^{\circ} \mathrm{C}$ [15]. 
interactions between C. gigas and pathogenic bacterial strains belonging to Vibrio aestuarianus and V. splendidus are well documented in the literature [reviewed by 16]. In contrast, there is a lack of information about mollusc antiviral immunity in the aetiology of "POMS". Oysters injected with poly I:C are induced into an antiviral state preventing subsequent OsHV-1 $\mu$ var infection [17]. Poly I:C is a synthetic dsRNA compound that mimics a virus because nearly all viruses produce dsRNA at some point during their replication [18]. Oysters have therefore been shown to recognise these virus-associated molecular patterns [19] and to induce an immune response that either inhibits virus entry or replication [17]. Previous research has shown that C. gigas hemolymph contains a compound(s) that inhibits herpes simplex virus type 1 (HSV-1) replication in Vero cell monolayers [20,21] and that OsHV-1 infection up-regulates expression of immune genes in hemocytes collected from adult C. gigas [22]. To date, investigations into the influence of water temperature and host ontogeny on the antiviral response of $C$. gigas have not been undertaken.

Here, we address the effect of temperature and host ontogeny on the antiviral response of C. gigas. Specifically, we hypothesize that (i) the oyster's antiviral response is compromised at elevated water temperatures and (ii) the antiviral response of adults and juvenile oysters is comparable. We test these hypotheses using a multifactorial experimental design by acclimating juvenile and adult C. gigas to 12 and $22^{\circ} \mathrm{C}$ and measuring their immune response to poly I:C in comparison to sterile seawater controls. These temperatures were chosen because OsHV-1 causes mortality in France, USA and Australia between $16-25^{\circ} \mathrm{C}[2,8,11]$, whereas OsHV-1 $\mu$ var is unable to be transmitted from positive to naïve oysters at temperatures below $13^{\circ} \mathrm{C}$ [12]. Our results support the hypothesis that the physiology of juvenile oysters contributes to the aetiology of Pacific oyster mortality syndrome.

\subsection{Materials and Methods}

\subsection{Animals and experimental conditions}

Adult (1.5 years) and juvenile (0.8 years) Pacific oysters (wet weight: $11.45 \pm 0.64$ \& $6.23 \pm 1.1$ grams, respectively) were kindly donated by Zippel Enterprises Pty Ltd, Smoky Bay, South Australia. Adult and juvenile oysters originated from the same family line spawned in January and September of 2012, respectively. Oysters were raised using standard commercial farming techniques. Oysters were delivered to Flinders 
118 University in June 2013 by overnight courier and immediately placed in seawater 119 recirculation system (salinity $35 \mathrm{ppt}$, temperature $16^{\circ} \mathrm{C}$ ). Prior to experimentation, a 120 notch was filed in the shell adjacent to adductor muscle of each oyster using an electric 121 bench grinder. Oysters were then returned to their recirculation system to recover for 12224 hours. Next, oysters were transferred to aerated aquariums (40 L) maintained at 123 either 12 or $22^{\circ} \mathrm{C}$ and allowed to acclimatize for one week before experimentation. 124 Water quality was assessed daily and oysters were not fed during this period.

125 At time 0 hours (prior to injection), juvenile and adult oysters maintained in 126 aquaria at either 12 or $22^{\circ} \mathrm{C}$ were injected in the adductor muscle with either poly I:C 127 (Sigma, Cat\# P0913, 5 mg.mL ${ }^{-1}$ in seawater) or sterile seawater (control) using a 25128 gauge needle attached to a multi-dispensing pipette. Juvenile and adult oysters were 129 injected with either 50 or $100 \mu$ of poly I:C or seawater, respectively. Hemolymph 130 samples were taken, using a sterile 23-gauge needle attached to a $1 \mathrm{~mL}$ syringe, from the 131 adductor muscle of four individual oysters from each group at 0,12 and 26 hours post132 injection. Hemolymph was immediately centrifuged, and hemocyte cell pellets and cell133 free hemolymph was snap frozen in liquid nitrogen and stored at $-80^{\circ} \mathrm{C}$.

134

$135 \quad 2.2$ Total RNA extraction, first-strand synthesis and qPCR.

136 Total RNA was extracted from hemocyte pellets using the Isolate II RNA mini kit 137 (Bioline) with on-column DNAse treatment following the manufacturer's protocol. The 138 purity and quantity of purified RNA was estimated by spectrophometry (Thermo 139 Scientific, ND-1000). First-strand synthesis was performed on $150 \mathrm{ng}$ of total RNA using 140 the Tetro cDNA synthesis kit (Bioline) following the manufacturers protocol. cDNA was 141 diluted in ten-volumes of sterile water prior to use.

142 Twenty putative antiviral genes were selected for RT-qPCR analysis using the 143 gene specific primers listed in Table 1. The PCR reaction volume was $6 \mu$ l and contained 144 SensiFAST TM SYBR Lo-ROX master mix (Bioline), $100 \mathrm{nM}$ of each specific primer and 1.5 145 ng of cDNA in a ViiA7TM thermocycler (Applied Biosystems) using an initial denaturation $146\left(95^{\circ} \mathrm{C}\right.$ for $\left.2 \mathrm{~min}\right)$ followed by 40 cycles of denaturation $\left(95^{\circ} \mathrm{C}, 5 \mathrm{sec}\right)$ and hybridisation147 elongation step $\left(60^{\circ} \mathrm{C}, 30 \mathrm{sec}\right)$. A subsequent melting temperature curve of the amplicon 148 was performed. Expression of target genes were normalised with the elongation factor 149 1-alpha reference gene [23], which was stable in the current study $(p>0.05, \mathrm{CV}=2.2 \%)$. 
150 The relative expression of target genes was calculated using the $\Delta \mathrm{Ct}$ method using the

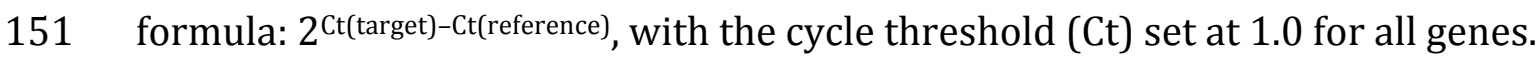

1532.3 Antiviral activity of hemolymph against HSV-1

154 Antiviral activity of cell-free hemolymph against herpes simplex virus type 1 (HSV-1) 155 was determined by plaque assay, as described $[20,24]$. Briefly, Vero cell monolayers in 156 24-well plates were infected in duplicate with 50 plaque forming units (PFU), in a total 157 volume of $0.56 \mathrm{ml}$, in the presence of hemolymph (8\% v/v). Hemolymph was pre158 incubated with the cell monolayers for 15 minutes prior to the addition of HSV-1 and the 159 hemolymph was included for the duration of the assay. Cells were incubated for 2 days 160 at $37^{\circ} \mathrm{C}$ before monolayers were fixed with $37 \%$ formaldehyde, stained with $2 \%$ 161 toluidine blue and plaques counted using an inverted light microscope (Olympus CK2). 162 Antiviral activity was expressed as percentage reduction in plaque numbers.

\subsection{Statistical analysis}

To determine statistical differences, univariate data was analysed using the computer software package, SPSS v.20 and differences were considered significant when $p<0.05$. Four-way analysis of variance (ANOVA) was performed to test differences in gene expression and antiviral activity of the hemolymph against HSV-1. The four factors analysed were 'TREATMENT' with the levels 'poly I:C' and 'control', 'HOST ONTOGENY' with levels of 'adults' and 'juveniles', 'WATER TEMPERATURE' with levels of ' $12^{\circ} \mathrm{C}$ ' and '22 ${ }^{\circ} \mathrm{C}$ ' and 'TIME-POINT' with three levels $(0,12 \& 26$ hours). Pairwise comparisons were performed using Tukey's HSD test when significant interactions between factors were identified. Normality and homogeneity of equal variances was assessed using

174 Levene's test of equal variances and residual plots. Gene expression data that was skewed was log-transformed in order to meet the requirements for ANOVA.

To test the overall immune gene response, permutational multivariate analysis of 177 variance (PERMANOVA) and principle component ordination (PCO) analyses were 178 conducted using PRIMER V.6 + PERMONANOVA (Plymouth Marine Laboratory, UK) [25].

179 Similarity matrices were prepared using Euclidean distance and 9999 permutations of 180 residuals were performed under a full model. Pair-wise tests were performed on 181 significant interaction terms $(p<0.05)$. PCO was used to produce scatter plots to 182 visually represent the multivariate differences among the significant factors. Vectors 
183

184

185

186

187

188

189

190

191

192

193

194

195

196

197

198

199

200

201

202

203

204

205

206

207

208

209

210

211

212

213

214

215

overlaid on the graphs were based on variables (genes) with $>0.8$ correlations to the two primary PCO axes.

\subsection{Results}

\subsection{Gene expression}

The experimental design allowed us to investigate the influence of water temperature, age and the interaction of water temperature and age on the antiviral response of $C$. gigas. We measured the expression kinetics of 20 putative antiviral genes, which were normalised to the expression of elongation factor 1-alpha [23]. Elongation factor 1-alpha was found to be stable in the current study (CV $=2.2 \%, p>0.05)$. Injection of seawater (control) into the adductor muscle of $C$. gigas did not alter the mRNA levels of any of the target genes investigated. Poly I:C did increase the hemocyte mRNA levels of TLR, MyD88, IкB-1, Rel, MDA5, STING, IRF, SOC, PKR, viperin and Mpeg1 (Figure 1, $p<0.01$ ).

Temperature and age were both found to influence the response of these genes to poly $\mathrm{I}: \mathrm{C}$ injection. At $22^{\circ} \mathrm{C}$, hemocytes from juvenile oysters had increased mRNA levels of TLR, MyD88, Rel, MDA5, IRF, SOC, PKR, viperin and Mpeg1 at 12 hours post-injection (Figure $1, p<0.05$ ). In contrast, the response of adult oysters at $22^{\circ} \mathrm{C}$ was delayed, with increased mRNA levels of TLR, IRF, MDA5, STING, viperin and Mpeg1 occurring at 26 hours post-injection (Figure 1, $p<0.05$ ). In adults, no up-regulation of individual target genes was observed at 12 hours post-injection $(p>0.05)$. At $12^{\circ} \mathrm{C}$, the antiviral response of juvenile oysters was inhibited with no significant change in mRNA levels at 12 or 26 hours post-injection (Figure $1, p>0.05$ ). Temperature also delayed the antiviral response of adult oysters at $12^{\circ} \mathrm{C}$ with only IRF and SOC being up-regulated at 26 hours post-injection (Figure 1, $p<0.05$ ).

Poly I:C, temperature, age and their respective interactions had no significant effect on mRNA levels of IкB-2, IK cytokine, cytokine receptors 1 and 2, IL-17D, IL-17D receptor, NOS, and multi-copper oxidase (Figure 1, $p>0.05$ ). Temperature influenced mRNA levels of MPO $(p<0.01)$, with a 0.54 -fold decrease in the expression of MPO at $22^{\circ} \mathrm{C}$ compared to $12^{\circ} \mathrm{C}$.

Multivariate PERMANOVA revealed no significant four-way interactions between treatment, ontogeny, temperature and time (pseudo $\mathrm{F}=0.243, p=0.845$ ). However, there were significant three-way interactions between injection $x$ ontogeny $x$ temperature (pseudo $\mathrm{F}=3.346, p=0.044$ ), as well as between treatment $\mathrm{x}$ temperature 
$216 \mathrm{x}$ time (pseudo $\mathrm{F}=5.286, p=0.01$ ). Pairwise tests confirmed the finding above by 217 revealing that the effects of poly I:C injection were significant at both temperatures for 218 adult oysters $(p<0.005)$, whereas juvenile only showed a significant response to poly $219 \mathrm{I}: \mathrm{C}$ injection at $22^{\circ} \mathrm{C}(p<0.0001)$, but not at $12^{\circ} \mathrm{C}(p=0.061)$.

PCO was able to account for $87.4 \%$ of the variation in the data on two axes

221 (Figure 2). The injection controls were found to group tightly towards the right hand 222 side of the plot, whereas the poly I:C injected oysters showed much greater variability 223 (Figure 2A). The difference between controls and poly I:C was driven by a large number 224 of genes, including SOC1, IRF, Viperin, TLR, Rel, PKR, MDA5 and Mpeg1 (Figure 2). The 225 effects of temperature appear more visible along the second PCO Y axis, with oysters 226 exposed to $12^{\circ} \mathrm{C}$ separating out higher on the plot compared to those at $22^{\circ} \mathrm{C}$ (Figure $2 \mathrm{~A}$ 227 \& 2B). The temperature effect is largely driven by difference in Cytk-R2, which is 228 negatively correlated to IKB-1 expression levels (Figure 2A). Adults and juveniles 229 showed a similar spread in the data points, with the effects of temperature (Figure 2B) 230 and injection treatment apparent at both developmental stages. The interaction 231 between time and treatment can be seen along PCO1 in Figure 2C, with the data taken at 232 time 0 hours clustering with all the controls towards the right of the plot, and much 233 more variation in the poly I:C injected oysters after 12 and 26 hours (Figure 2C).

\subsection{Humoral factors}

236 The hemolymph of C. gigas exhibited anti-HSV-1 activity. Addition of cell-free 237 hemolymph to Vero cell monolayers ( $8 \% \mathrm{v} / \mathrm{v})$ reduced the number of HSV-1 plaques by $23862.2 \%$. Treatment, age, temperature and their interactions did not alter the anti-HSV-1 239 activity of the hemolymph ( $p>0.05$, data not presented).

\subsection{Discussion}

242 Herpesviruses pose a large threat to worldwide production of Pacific oysters. Field and 243 laboratory studies have revealed younger developmental stages of $C$. gigas are more 244 sensitive to infection by OsHV-1 $\mu$ var $[2,7,8]$, and mortality coincides with water 245 temperatures between 17 to $24^{\circ} \mathrm{C}[7,8]$. It has often been suggested that the increased 246 mortality of younger $C$. gigas reflects an immature immune system [2, 10, 26]. High 247 water temperatures and associated low dissolved oxygen may further compromise their 
immune system. Our study showed that juvenile oysters at $22^{\circ} \mathrm{C}$ respond vigorously to a virus-associated molecular pattern.

To date, two studies have investigated the antiviral response of $C$. gigas against OsHV-1 and both these studies have demonstrated that the immune system of $C$. gigas is not ignorant of virus infection with increased expression of genes involved in virus recognition, signalling and immunity $[17,22]$. Oysters can recognise different virusassociated molecular patterns and can respond in a specific manner at the transcriptional level [19]. Numerous studies have demonstrated that the hemolymph of C. gigas contains a compound(s) with broad-spectrum antiviral activity [20, 21, 27, 28]. These compounds are yet to be identified, but display virucidal activity against HSV-1 and also inhibit HSV-1 replication [28]. In the current study, we measured cellular and humoral responses to a virus-associated molecular pattern. We chose poly I:C because previous research has demonstrated it induces the same antiviral gene expression profiles as experimental infection with OsHV-1 $\mu$ var [17]. In the current study, poly I:C appears to induce a cellular response targeted at preventing virus transcription and replication as opposed to inducing the production and/or release of humoral antiviral (anti-HSV-1) compounds. This observation is consistent with a previous study measuring the antiviral activity of the hemolymph of hybrid abalone, Haliotis rubra $\mathrm{x}$ laevigata infected with abalone herpesvirus (AbHV-1) [29]. Seasonal variations in the anti-HSV-1 activity of the hemolymph have been reported for C. gigas and H. rubra with both species displaying higher anti-HSV-1 activity during summer [20,30]. In contrast, we observed that temperature and oyster age had no effect on anti-HSV-1 activity of the hemolymph of $C$. gigas, suggesting the antiviral compounds are constitutively expressed.

Double-stranded RNA, either viral or synthetic, is an efficient inducer of interferon signalling pathways in vertebrates [18]. The antiviral action of interferon is mediated by a two-step pathway, which has been characterised in detail and reviewed comprehensively $[18,31]$. Typically, transcription of the interferon gene occurs when virus-infected cells recognise dsRNA produced during virus replication [18]. Vertebrate cells recognise dsRNA using an evolutionarily conserved set of pattern recognition receptors, including toll-like receptor 3 (TLR3) and members of retinoic acid inducible gene I (RIG-1) family [18]. Upon recognition of dsRNA, these receptors initiate complex signalling pathways resulting in IRF-3 (interferon regulatory factor 3 ) and NF- $\mathrm{B}$ assembling on the promoter region of the interferon gene [18]. Interferon is then 
secreted by virus-infected cells [31]. Interferon exerts an antiviral effect by binding to interferon receptors on neighbouring cells and triggers signal transduction through the JAK (Janus activated kinase)-STAT (signal transducer and activation of transcription) pathway resulting in up-regulation of several hundred interferon-stimulated genes (ISGs), including protein kinase R (PKR), 2'5'-oligoadenylate synthetase (OAS), Mx and viperin $[18,31]$.

No invertebrate has been shown to have an obvious homolog of interferon [32]. However, an equivalent pathway is likely present in the oyster (Figure 3) [17]. In the current study, poly I:C induced expression of putative dsRNA recognition receptors (TLR \& MDA5), downstream signalling molecules (MyD88, IкB-1, Rel, STING, IRF \& SOC-1) and several interferon-stimulated genes (PKR \& viperin) (Figure 1), which suggests at least two dsRNA-signalling pathways (TLR-dependent \& MDA5-dependent) are present in the oyster (see Figure 3). PCO revealed positive correlatons in the expression of most of these receptor and signalling genes in response to poly I:C injection (Figure 2), suggesting that these two pathway are initiated simultaneously. The purpose of the vertebrate interferon pathway is to induce ISGs that limit synthesis of viral proteins and induce programmed cell death (autophagy and apoptosis) of virus-infected cells [18, 33]. Data in Genbank suggests the oyster possesses several classic ISGs, including PKR, OAS, Mx, ADAR and viperin. PKR has been studied intensively and in response to its cofactor, dsRNA, it undergoes activation to inhibit viral and cellular protein synthesis by phosphorylating eukaryotic initiation factor 2 (eIF2) [18]. PKR is also required for viral induced autophagy and apoptosis [34]. Viperin's mode of action is unclear, but it may impair virus budding [33].

Relatively few studies have investigated the influence of temperature or host ontogeny on the immunological response of C. gigas [35-38]. In vivo and vitro studies suggest $C$. gigas is immunocompromised at elevated seawater temperature $[35,36]$. $C$. gigas at $21^{\circ} \mathrm{C}$ have reduced numbers of hemocytes. $\mathrm{mL}^{-1}$ and decreased phagocytosis activity in the hemolymph compared to oysters at $12^{\circ} \mathrm{C}$ [36]. Our results provide the first evidence that temperature and host ontogeny influence the antiviral response of $C$. gigas (Figure 1). Complex interactions appear to occur with temperature over time, and 311 whilst some genes such as Cytk-R2 appear to suppressed at $22^{\circ} \mathrm{C}$, others such as Cytk-R1 312 and IкB-1 were elevated in response to the higher temperature (Figure 1 \& 2). Similarly, 313 trade-offs between antibacterial and antiviral immune responses have been reported for 
314 abalone under temperature stress [30]. However, in contrast to previous studies 315 investigating the immunological response to bacteria infections $[35,36], 12^{\circ} \mathrm{C}$ delayed 316 the antiviral response of adults and inhibited the response of juveniles. At $22^{\circ} \mathrm{C}$, juvenile 317 oysters responded vigorously to poly I:C injection (Figure 1). Experimental trials show 318 mortality of juvenile $C$. gigas peaks within three days after infection with OsHV-1 $\mu$ var $319[26,39]$ and peak mortality of adults occurs after juveniles (authors personal 320 observations). We speculate whether the vigorous response of juvenile oysters results in 321 a "cytokine storm" leading to tissue dysfunction and death of the oyster. The antiviral 322 response observed would prevent transcription and translation of host and virus 323 proteins (program cell death) and may explain the multifocal and extensive ulcerative 324 lesions observed in epithelium tissue of $C$. gigas infected with OsHV-1 $\mu$ var [2].

325 The antiviral response of $C$. gigas against poly I:C may show differences to the 326 response against OsHV-1 $\mu$ var. All viruses have evolved mechanisms to circumvent and 327 modulate the host immune response [18]. In the present study, a high proportion of the 328 inducible genes (TLR, IRF, Rel, PKR \& Mpeg1) are also up-regulated in C. gigas in 329 response to experimental OsHV-1 infection $[17,22]$. We were surprised that IK 330 cytokine, myeloperoxidase (MPO) and the multi-copper oxidase were not induced in this 331 study (Figure 1). Experimental herpesvirus infections in the scallop, Chlamys farreri 332 with acute viral necrobiotic virus (AVNV) have found increased plasma enzyme 333 activities for MPO and phenoloxidase [40] and increased hemocyte mRNA transcript 334 levels for a multicopper oxidase (phenoloxidase) [41]. Likewise, C. gigas up-regulates a multicopper oxidase and IK cytokine in response to OsHV-1 [22]. The failure of poly I:C

336 to induce the expression of MPO and multicopper oxidase (Figure 1) suggests these 337 genes are induced by other virus-associated molecular patterns, damage-associated 338 molecular patterns (DAMPs) or microbial components associated with herpesvirus 339 infection (i.e. Vibrio sp.). Previous studies have demonstrated IK cytokine is up340 regulated in the Sydney rock oyster, Saccostrea glomerata in response to poly I:C [19].

\section{Conclusion}

343 Presence of OsHV-1 $\mu$ var is insufficient on its own to cause significant mortality of 344 juvenile C. gigas [4]. Host ontogeny and water temperature are causal factors in the 345 aetiology of Pacific oyster mortality syndrome. Our results demonstrate C. gigas relies 346 on a cellular response to prevent virus replication and this antiviral response is 
influenced both by seawater temperature and host ontogeny. Whether the vigorous antiviral response of juvenile oysters at $22^{\circ} \mathrm{C}$ results in an immune mediated disorder leading to higher mortality is worthy of further investigation. Future studies should focus on comparing the antiviral response of adult and juvenile C. gigas against OsHV-1 $\mu v a r$.

\section{Acknowledgements}

354 The authors acknowledge the donation of oysters from Gary Zippel, laboratory assistance from David White and research funds provided by the Australian Seafood Cooperative Research Centre (Grant: 2011/758).

1. Wendling CC, Wegner KM. Relative contribution of reproductive investment, thermal stress and Vibrio infection to summer mortality phenomena in Pacific oysters. Aquaculture. 2013 412:88-96.

2. Jenkins C, Hick P, Gabor M, Spiers Z, Fell SA, Gu X, et al. Identification and characterisation of an ostreid herpesvirus-1 microvariant (OsHV-1 u-var) in Crassostrea gigas (Pacific oysters) in Australia. Dis Aquat Org. 2013 105:109-26.

3. Segarra A, Pepin JF, Arzul I, Morga B, Faury N, Renault T. Detection and description of a particular Ostreid herpesvirus 1 genotype associated with massive mortality outbreaks of Pacific oysters, Crassostrea gigas, in France in 2008. Virus Res. 2010 153:92-9.

4. $\quad$ Paul-Pont I, Dhand NK, Whittington RJ. Spatial distribution of mortality in Pacific oyster Crassostrea gigas: reflection on mechanisms of OsHV-1 transmission. Dis Aquat Org. 2013.

5. Renault T, Moreau P, Faury N, Pepin J-F, Segarra A, Webb S. Analysis of clinical ostreid herpesvirus 1 (Malacoherpesviridae) specimens by sequencing amplified frangments from three virus genome areas. Journal of Virology. 2012 86:5942-7.

6. Paul-Pont I, Dhand NK, Whittington RJ. Influence of husbandry practices on OsHV-1 associated mortality of Pacific oysters Crassostrea gigas. Aquaculture. 2013 412413:202-14.

7. Peeler EJ, Allan Reese R, Cheslett D, Geoghegan F, Power A, Thrush MA. Investigation of mortality in Pacific oysters associated with Ostreid herpevirus-1 uvar in the Republic of Ireland in 20089. Prev Vet Med. 2012 105:136-43.

8. Pernet F, Barret J, Le Gall P, Corporeau C, LDegremont L, Lagarde F, et al. Mass mortalities of Pacific oysters Crassostrea gigas reflect infectious diseases and vary with farming practices in the Mediterranean Thau lagoon, France. Aquaculture Environ Interact. 2012 2:215-37.

9. Dégremont L. Evidence of herpesvirus (OsHV-1) resistance in juvenile Crassostrea gigas selected for high resistance to the summer mortality phenomenon. Aquaculture. 2011 317:94-8. 

herpesvirus 1 detection and relationship with Crassostrea gigas spat mortality in France between 1998 and 2006. Vet Res. 2011 42:73-84. 11. Burge CA, Griffin FJ, Friedman CS. Mortality and herpesvirus infections of the Pacific oyster Crassostrea gigas in Tomales Bay, California, USA. Dis Aquat Org. 2006 72:31-43.

12. Petton B, Pernet F, Robert R, Boudry P. Temperature influence on pathogen transmission and subsequent mortalities in juvenile Pacific oysters Crassostrea gigas. Aquacult Environ Interact. 2013 3:257-73.

398 13. St-Hilaire S, Beevers N, Way K, Le Deuff RM, Martin P, Joiner C. Reactivation of koi herpesvirus infection in common carp (Cyprinus carpio). Dis Aquat Org. 2005 67:15-23. 14. Wang X, Wang L, Zhang H, Ji Q, Song L, Qiu L, et al. Immune response and energy metabolism of Chlamys farreri under anguillarum challenge and high temperature exposure. Fish Shellfish Immunol. 2012 33:1016-26.

403 15. Beaz-Hidalgo R, Balboa S, Romalde JL, Figueras MJ. Diversity and pathogenecity of Vibrio species in cultured bivalve molluscs. Environ Microbiol Rep. 2010 2:34-43. 16. Schmitt P, Duperthuy M, Montagnani C, Bachere E, Destoumieux-Garzon D. Immune responses in the Pacific oyster Crassostrea gigas: an overview with focus on summer mortalities. In: Qin JG, editor. Oysters: physiology, ecological distribution and mortality: Nova Science Publishers; 2011, p. 311. 17. Green TJ, Montagnani C. Poly I:C induces a protective antiviral immune response in the Pacific oyster (Crassostrea gigas) against subsequent challenge with Ostreid herpesvirus (OsHV-1 $\mu$ var). Fish Shellfish Immunol. 2013 35:382-8.

18. Randall RE, Goodbourn S. Interferons and viruses: an interplay between induction, signalling, antiviral responses and viral countermeasures. J Gen Virol. 2008 89:1-47.

19. Green TJ, Barnes AC. Inhibitor of REL/NF-kB is regulated in Sydney rock oysters in response to specific double-stranded RNA and Vibrio alginolyticus, but the major immune anti-oxidants EcSOD and Prx6 are non-inducible. Fish Shellfish Immunol. 2009 $27: 260-5$. HSV-1 activity in different extracts from Pacific oysters Crassostrea gigas. Dis Aquat Org. 2005 67:141-7.

21. Olicard C, Renault T, Torhy C, Benmansour A, Bourgougnon N. Putative antiviral activity in hemolymph from adult Pacific oysters, Crassostrea gigas. Antiviral Res. 2005 66:147-52.

22. Renault T, Faury N, Barbosa-Solomieu V, Moreau K. Suppression substractive hybridisation (SSH) and real time PCR reveal differential gene expression in the Pacific cupped oyster, Crassostrea gigas, challenged with Ostreid herpesvirus 1. Dev Comp Immunol. 2011 35:725-35.

23. de Lorgeril J, Zenagui R, Rosa R, Piquemal D, Bachere E. Whole transcriptome profiling of successful immune response to Vibrio infections in the oyster Crassostrea gigas by digital gene expression analysis. Plos One. 2011 6:e23142.

24. Dang VT, Speck P, Doroudi M, Smith B, Benkendorff K. Variation in the antiviral and antibacterial activity of abalone Haliotis laevigata, H. rubra and their hybrid in South Australia. Aquaculture. 2011 315:242-9.

25. Anderson MJ, Gorley RN, Clarke KR. PERMANOVA+ for PRIMER: Guide to software and statistical methods.: Plymouth Marine Laboratory; 2008. 

infection of Pacific oyster Crassostrea gigas spat by ostreid herpesvirus 1: demonstration of oyster spat susceptibility. Vet Res. 2011 42:27.

27. Zeng M, CUI W, Zhao Y, Liu Z, Dong S, Guo Y. Antiviral active peptide from oyster. Chinese Journal of Oceanology and Limnology. 2008 26:307-12. of antiviral activity in the hemolymph from oysters Crassostrea rhizophorae and Crassostreea gigas. Aquat Living Resour. 2006 19:189-93. laevigata and Haliotis rubra hybrids. Fish Shellfish Immunol. 2013 34:688-91.

30. Dang VT, Speck P, Benkendorff K. Influence of elevated temperatures on the immune response of abalone, Haliotis rubra. Fish Shellfish Immunol. 2012 32:732-40.

31. Robertsen B. The interferon system of teleost fish. Fish Shellfish Immunol. 2006 20:172-91.

32. Loker ES, Adema CM, Zhang S-M, Kepler TB. Invertebrate immune systems - not homogeneous, not simple, not well understood. Immunolog Rev. 2004 198:10-24.

33. Mattijseen S, Pruijn GJM. Viperin, a key player in the antiviral response. Microbes Infect. 2012 14:419-26.

34. He C, Klionsky DJ. Regulation mechanisms and signaling pathways of autophagy. Annu Rev Genet. 2009 43:67-93.

35. Gagnaire B, Frouin H, Moreau K, Thomas-Guyon H, Renault T. Effects of temperature and salinity on haemocyte activities of the Pacific oyster, Crassostrea gigas (Thunberg). Fish Shellfish Immunol. 2006 20:536-47.

36. Malham SK, Cotter E, O'Keeffe S, Lynch S, Culloty SC, King JW, et al. Summer mortality of the Pacific oyster, Crassostrea gigas, in the Irish Sea: The influence of temperature and nutrients on health and survival. Aquaculture. 2009 287:128-38.

37. Tirape' A, Bacque C, Brizard R, Vandenbulcke F, Boulo V. Expression of immunerelated genes in the oyster Crassostrea gigas during ontogenesis. Dev Comp Immunol. 2007 31:859-73.

38. Montagnani C, Tirape' A, Boulo V, Escoubas JM. The two Cg-timp mRNAs expressed in oyster hemocytes are generated by two gene families and differentially expressed during ontogenesis. Dev Comp Immunol. 2005 29:831-9.

39. Schikorski D, Faury N, Pepin JF, Saulnier D, Tourbiez D, Renault T. Experimental ostreid herpesvirus 1 infection of the Pacific oyster Crassostrea gigas: Kinetics of virus DNA detection by q-PCR in seawater and in oyster samples. Virus Res. 2011 155:28-34. 40. Xing J, Lin T, Zhan W. Variations of enzyme activities in the haemocytes of scallop Chlamys farreri after infection with the acute virus necrobiotic virus (AVNV). Fish Shellfish Immunol. 2008 25:847-52.

41. Chen G, Wang C, Zhang C, Wang Y, Xu Z, Wang C. A preliminary study of differentially expressed genes of the scallop Chlamys farreri against acute viral necrobiotic virus (AVNV). Fish Shellfish Immunol. 2013 34:1619-27.

42. Zhang Y, He X, Yu Z. Two homologues of inhibitor of NF-Kappa B (IkB) are involved in the immune defense of the Pacific oyster, Crassostrea gigas. Fish Shellfish Immunol. 2011 30:1354-61.

43. Montagnani C, Kappler C, Reichhart JM, Escoubas JM. Cg-Rel, the first Rel/NF-kB homolog characterized in a mollusk, the Pacific oyster Crassostrea gigas. FEBS Lett. 2004 561:75-82. 
485 44. Roberts S, Gueguen Y, Lorgeril Jd, Goetz F. Rapid accumulation of an interleukin 48617 homolog transcript in Crassostrea gigas hemocytes following bacterial exposure. Dev 487 Comp Immunol. 2008 32:1099-104.

488

489

490 


\section{Table Legend}

Table 1: Primer pairs used in RT qPCR expression analysis. The Genbank accession number and gene function is provided for each gene. Previously published primer pairs are referenced.

\section{Figure Legends}

497 Figure 1: Expression heat map (A) illustrating the average relative expression levels $498\left(2^{\Delta \mathrm{CT}}\right)$ for all target genes according to treatment, host ontogeny, water temperature and 499 time. For each gene, the largest expression values are displayed in red and the smallest 500 values in black. Relative expression for TLR (B), MDA-5 (C), STING (D), IRF (E), PKR (F) 501 and Viperin (G) are presented in individual graphs. Gene expression is presented 502 relative to the EFU house-keeping gene $\left(2^{\triangle \mathrm{CT}}\right.$, mean $\left.\pm \mathrm{SE}\right)$. Differences in relative gene 503 expression was determined using four-way analysis of variance (ANOVA). Asterisks

504 denote significant differences between poly I:C and control group $(p<0.05$, Tukey's 505 HSD).

Figure 2: Principle component ordination (PCO) for the multivariate gene expression in response to (A) temperature $\left(12\right.$ and $22^{\circ} \mathrm{C}$ labels) and injection with sterile seawater (black filled upwards triangles) or poly I:C (grey filled downward triangles); (B) temperature and ontogeny (juveniles = black filled downward triangles and adults $=$ grey filled upward triangles); and (C) time (0,12 \& 26 hour labels) and injection with sterile seawater (black filled upwards triangles) or poly I:C (grey filled downward triangles). Vector overlays indicate genes with correlation coefficients $>0.8$.

515 Figure 3: Conceptual diagram of the inducible antiviral response of Crassotrea gigas. We

516 hypothesize C. gigas recognises dsRNA using evolutionarily conserved dsRNA 517 recognition receptors (TLR \& MDA5). Upon recognistion, these receptors instigate TLR518 dependent and MDA5-dependent signalling resulting in the transcription factors, Rel 519 and IRF, to trans-locate to the cell nucleus resulting in the induction of cytokines and 520 antimicrobial peptides. Cytokines are secreted from viral infected cells. Cytokines 521 signal through the Jak-STAT pathway resulting in the induction of interferon stimulated genes (ISGs), such as protein kinase R (PKR) and viperin. 
Table 1

Primer pairs used in RT qPCR expression analysis. The Genbank accession number and gene function is provided for each gene. Previously published primer pairs are referenced.

\begin{tabular}{|c|c|c|c|c|c|}
\hline Gene & Function & Accession\# & Sense primer & Antisense primer & Reference \\
\hline EFU & Reference Gene & ABI22066 & GAGCGTGAACGTGGTATCAC & ACAGCACAGTCAGCCTGTGA & [23] \\
\hline TLR & Pathogen Recognition Receptor & & GCAGGACTCCACTTTCTCAC & GTTGGCACCCAGGTAAAGG & [17] \\
\hline MyD88 & Cell-Signalling & EKC40070 & GTGACTACACCAAGCAGGAC & GTACTGACCCTGAGTTCTGC & \\
\hline ІкB-1 & Cell-Signalling & DQ250326 & GAAAAAGTGGCAAGAGTGTC & GAAGAGTCATCGAAAGCAAC & [17] \\
\hline ІкB-2 & Cell-Signalling & HQ650768 & GCTCGGAAGTAAATGAAGTG & CTGGAGTTCTTGAGGTCTGC & [42] \\
\hline Rel & Cell-Signalling & AAK72690 & GCTGAACCAGAACCTCATGA & CGAAGGACATGTTCTGATCC & [43] \\
\hline MDA5 & Pathogen Recognition Receptor & EKC38304 & CAACAACATGGGAAGTATGGTG & TCGGTCTGTTAACTGCGGAC & \\
\hline STING & Cell-Signalling & ЕКС29965 & CTGCTATTGTCCGCCATC & GAATGGGCGTGGCATACTC & \\
\hline IRF & Cell-Signalling & EKC43155 & CGAAACGCAGAAACTGTTC & ATTTGCCTTCCATCTTTTGG & [17] \\
\hline IK Cytokine & Cell-Signalling & EF627976 & GGAGCGCGAGGAAGAGGAGATAATGG & ATCCGTCCCGGCAGAAACAGCTC & [22] \\
\hline Cytokine R1 & Cell-Signalling & & GTCGCACAGTCCGATACAAAT & AAGGCAACAGACTCGGGTATT & \\
\hline Cytokine R2 & Cell-Signalling & EKC24772 & AGCGCCTTTGTATGTGAGCTG & TGCTGGTCGCAGAGTTGAATG & \\
\hline SOC-1 & Cell-Signalling & EKC24772 & CAAGAGAGAATCTGTGGGAAC & GCATCTTAGCACTAATTCTCTC & \\
\hline IL-17D & Cell-Signalling & AB093467 & ACTGAGGCTCGATGCAAGTG & AGCCTTCTTGCTTCATGTGG & [44] \\
\hline IL-17D Receptor & Cell-Signalling & EKC22301 & TGATTGTGGACCAGCCTGAC & CACGATGATGAGACCCAGC & \\
\hline PKR & IFN Stimulated Gene & ЕКС34807 & GAGCATCAGCAAAGTGTTGAG & GTAGCACCAGGAGATGGTTC & [17] \\
\hline Viperin & IFN Stimulated Gene & EKC28205 & GCTTTGACCCGGAAACCAAC & TGACACCAATCCCGAACTCG & \\
\hline Mpeg1 & Effector Molecule & EF672979 & GCCACCGAAAGCCGGAGAAGATGTC & ACCGAGACCGAGTTTCAGGGGGTAG & [22] \\
\hline NOS & Effector Molecule & ЕКС33784 & GATGGGAAAAGCTCTAGCAAG & GTTTCCAAAGGTACTGGTCAC & \\
\hline MPO & Effector Molecule & ЕКC40014 & CGGGACGTTAGCAACATTC & TGCTCTCCGCAACATGATAG & \\
\hline Multicopper oxidase & Effector Molecule & EU678320 & TGGTTCCTGCATTGTCACAT & AAGAGTATCAGCCGCGAAAA & [22] \\
\hline
\end{tabular}




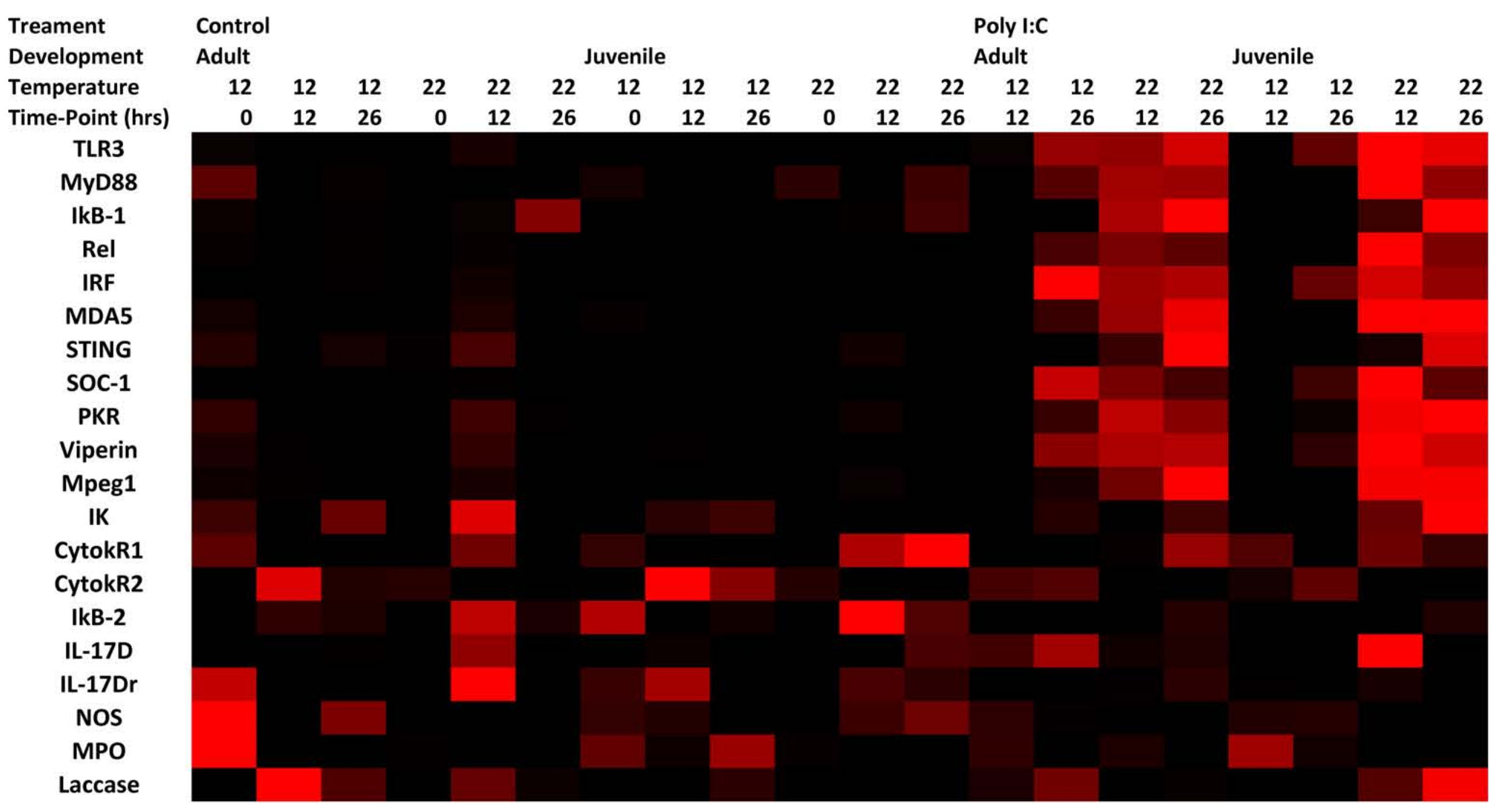

Low

Medium

High

B

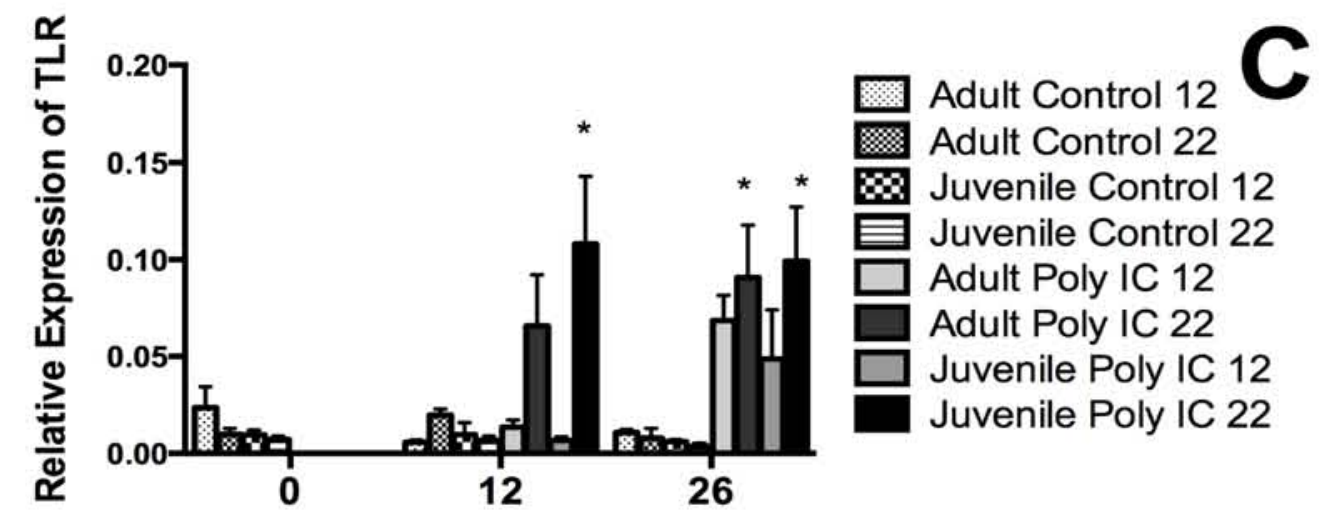

Time-Point
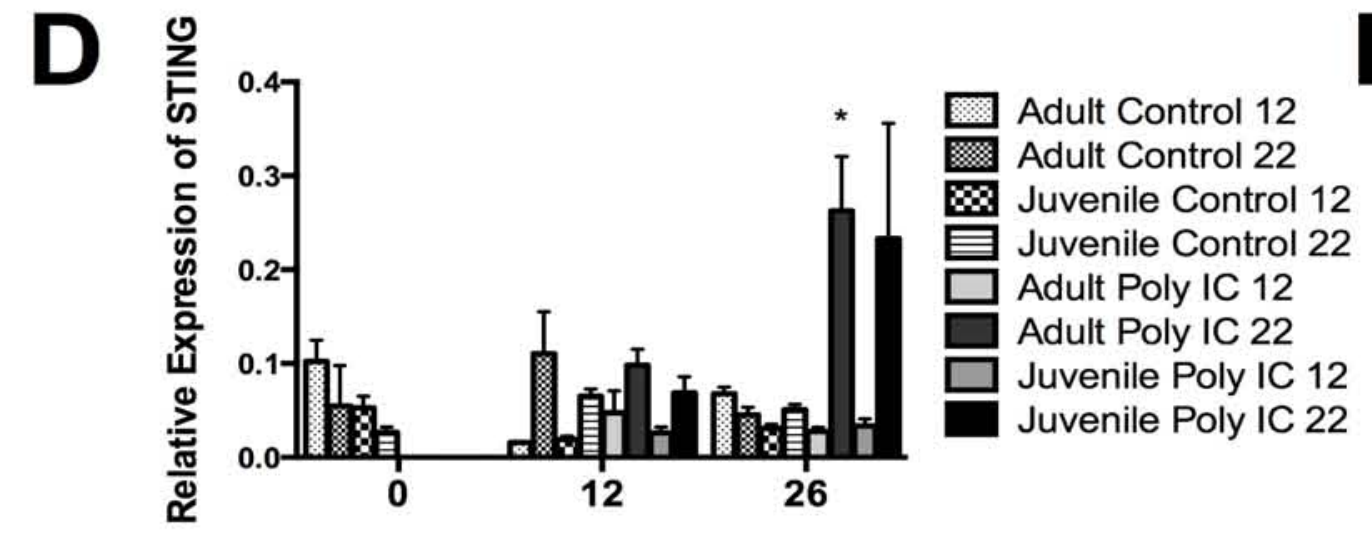

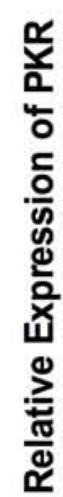

Time-Point

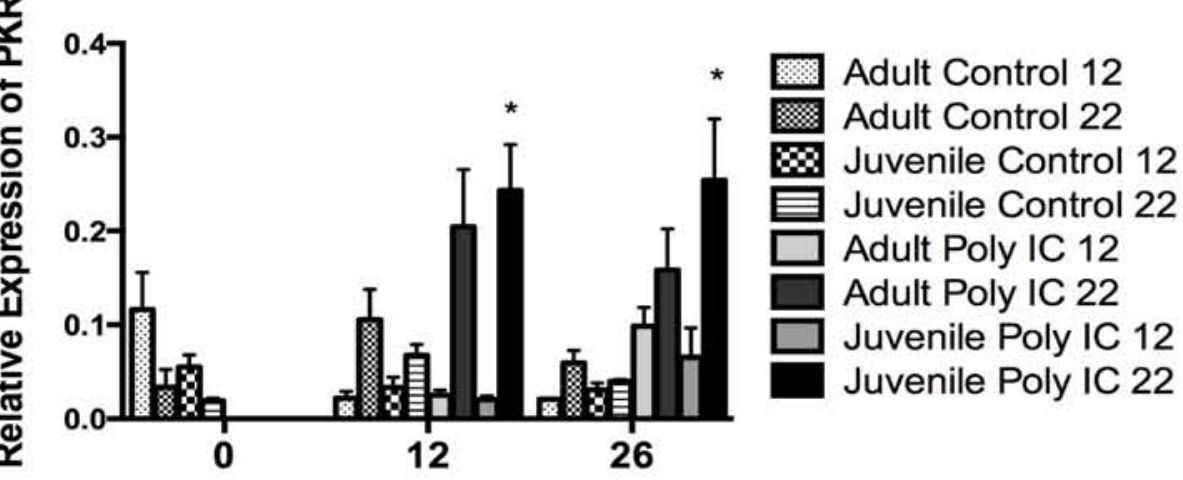

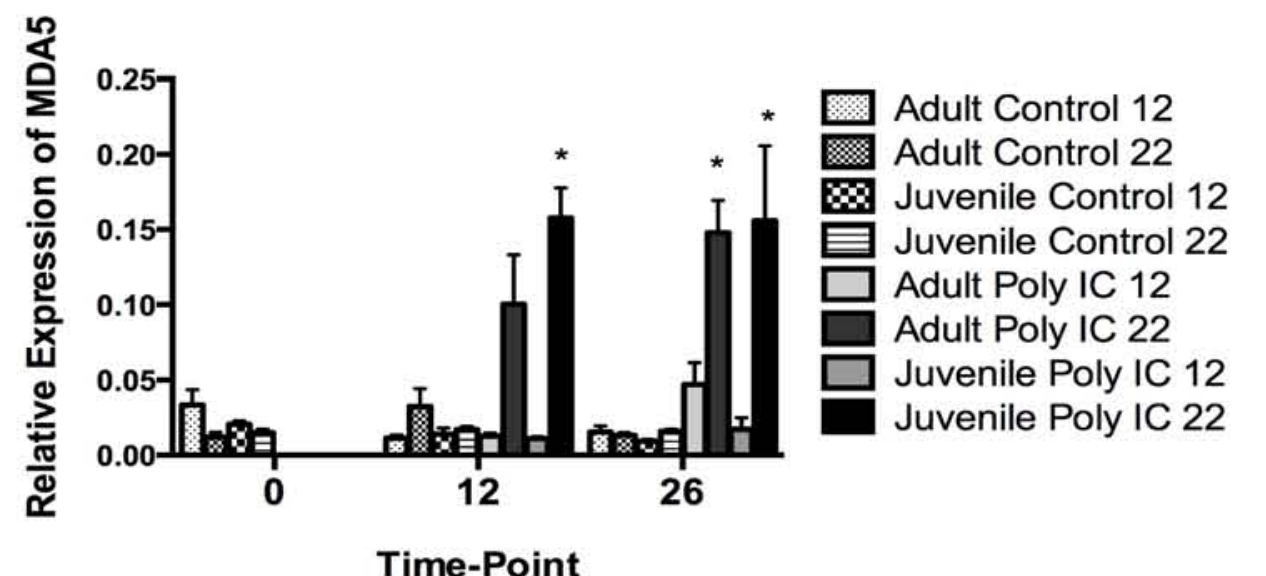

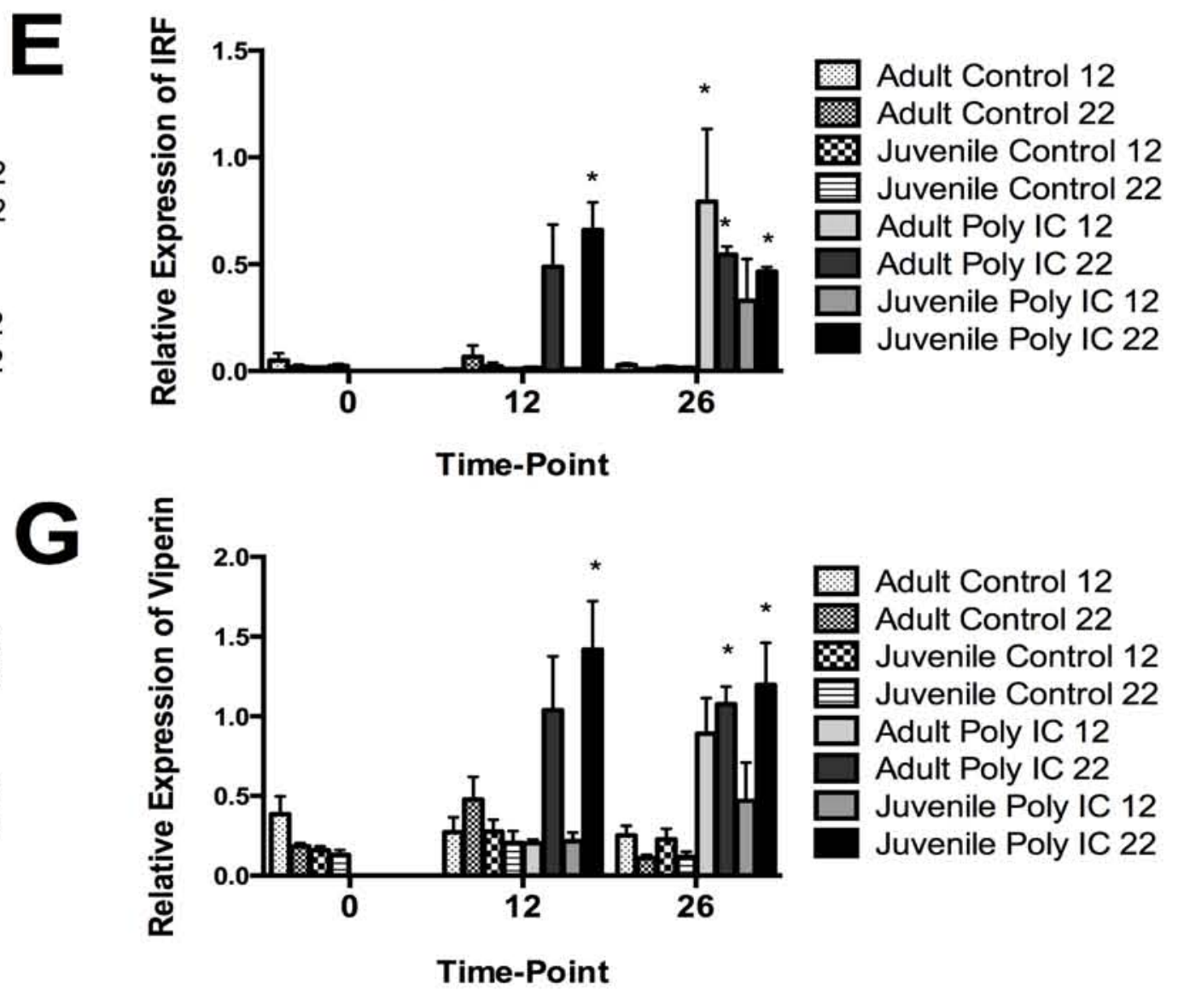


A

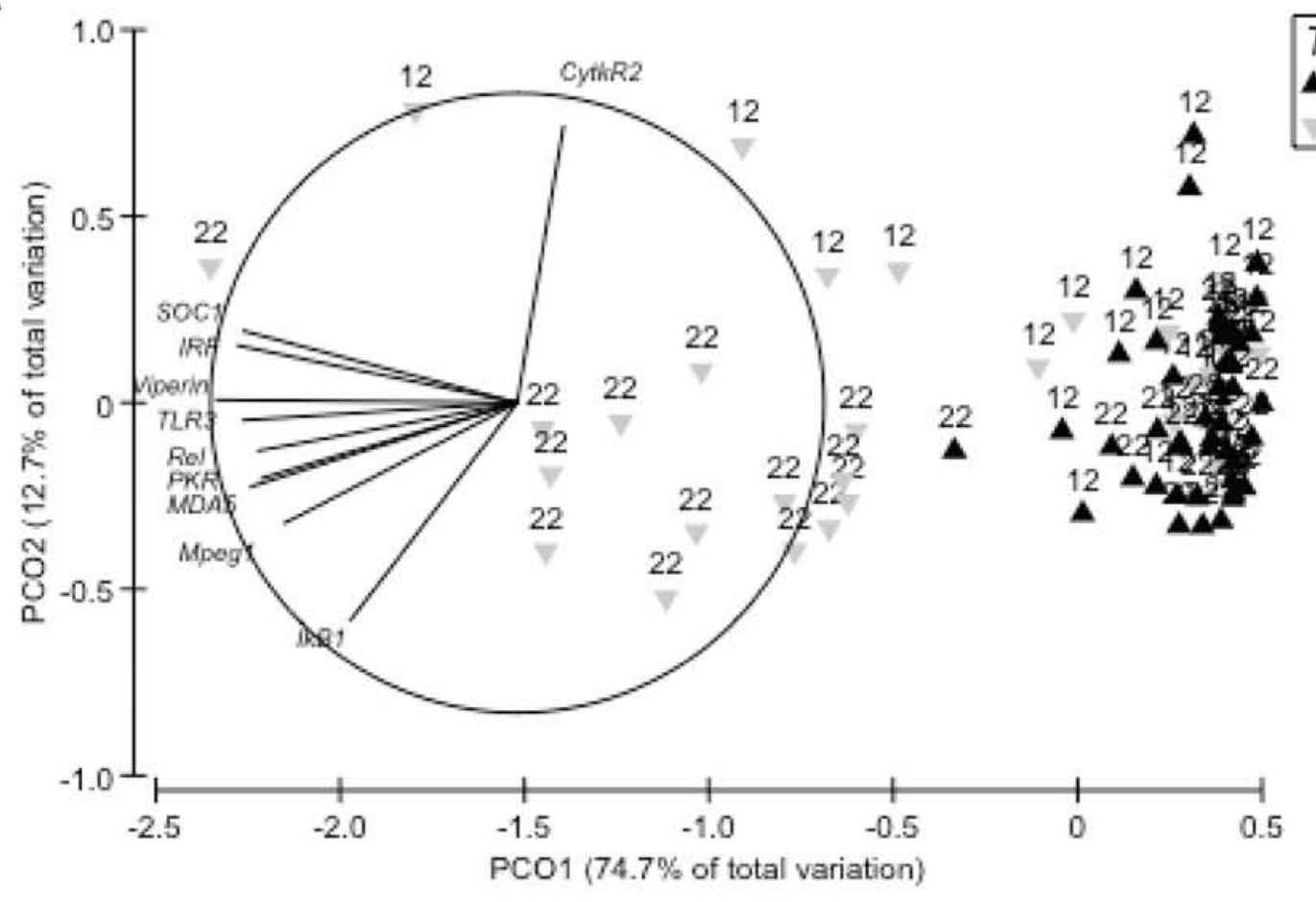

B

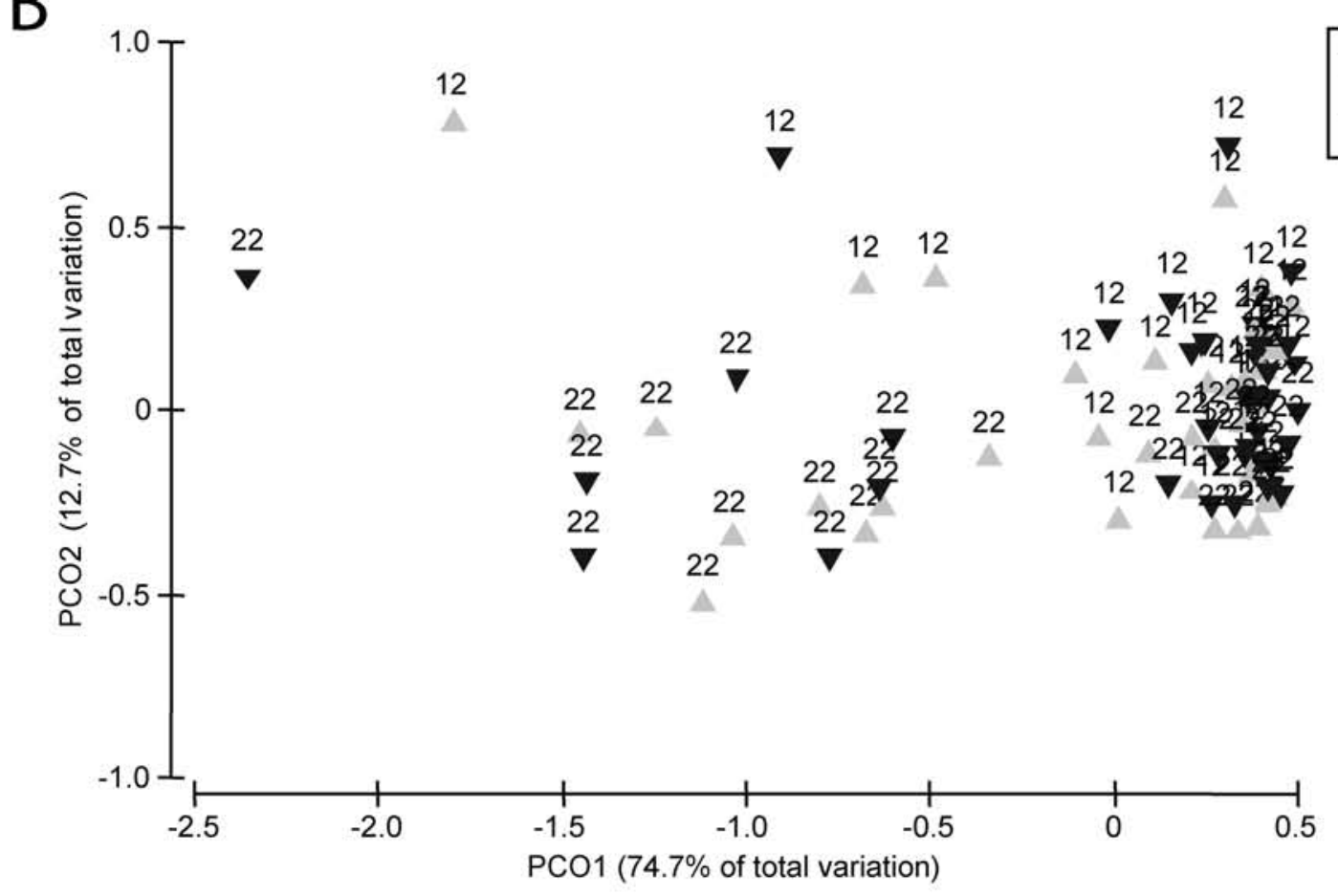

C

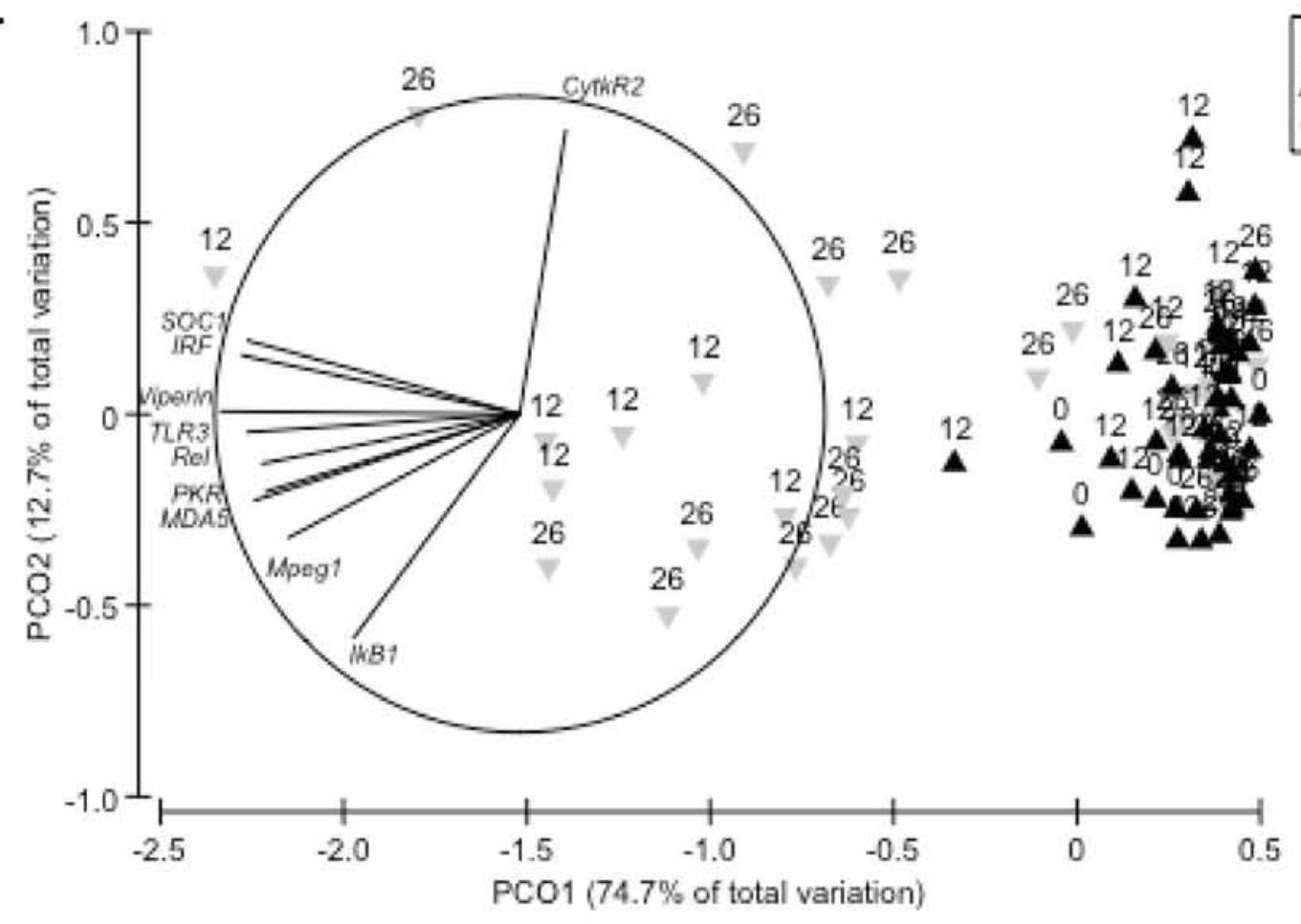

Treatment

A control

polyl:C 
